\title{
Shear behavior of the interface between expansive soil and sand liner during wetting-drying cycles
}

\author{
Yuan Jun-ping ${ }^{\text {i) }}$, Lin Yan-ling ${ }^{\text {ii) }}$, Ding Peng ${ }^{\text {ii) }}$, Wang Qiang-lin ${ }^{\text {ii) }}$
}

\begin{abstract}
i) Associate Professor, Geotechnical Engineering Research Institute, Key Laboratory of Ministry of Education for Geomechanics and Embankment Engineering, Hohai University, Nanjing 210098, China
\end{abstract}

ii) MSC Student, Geotechnical Engineering Research Institute, Hohai University, Nanjing, 210098, China.

\begin{abstract}
A series of direct shear tests are carried out on the interfaces between expansive soil and sand liner during wetting-drying cycles. Several factors impacting the shear behavior are discussed, including wetting-drying cycles and saturation methods. Upto 5 times of the wetting-drying cycles are applied on expansive soil-sand liner samples before shearing. Saturation methods comparison is carried out under confined and unconfined conditions, which means whether the samples are fully restricted in a saturator or are able to swell freely during saturation. Test results show that the interface behaves strain-hardening and the shear zone extents to a certain depth in sand liner. The shear strength is higher under confined saturation condition than that under unconfined saturation condition, the friction angles under confined saturation condition are about 0.4 to 9.7 degrees greater than those under unconfined saturation condition at the same wetting-drying cycle. As wetting-drying cycling, the friction angle increases under confined saturation condition, while it increases at beginning and then decreases under unconfined saturation condition. The mechanism of the interface friction angles behavior is revealed as the combination result of two aspects: sand particles merge into expansive soil and samples compacted by expansive force, which increases the density of the "shear band" and sample, and fissures grow, which destroys the integrity.
\end{abstract}

Keywords: expansive soil, wetting-drying cycles, interface, shear strength, sand liner

\section{INTRODUCTION}

The interaction between a structure and surrounded soil has been an important and hot topic in civil/geotechnical engineering for a long term. The main reason is because the properties of two sides on the interface are quite different, which leads to complicated behavior such as large stress/deformation gradient and easily extrusion/rupture when shearing. In order to find out the mechanism of the interaction between structure and surrounded soil, many researches have been done on different materials, such as concrete, steel, wood and geotextile for structure; clay, sand and gravel for surrounded soils (Desai, 1985; Tejchman, 1995). Impaction factors are taken into account including density, stiffness, void ratio and moisture content of surrounded soils, roughness and contact normal stress on the interface, saturation methods and test apparatus for laboratory tests. Two typical types of failure modes are widely accepted: 1) the failure happens exactly at the interface, when the roughness and normal stress on interface are relatively low; 2) the failure extents to a certain depth in soil, when the roughness and normal stress on interface are relatively high (Desai, 1985; Boulon, 1987; Hu, 2007).

So far by now, however, very few studies have been conducted on contact characteristics between two granular materials. A self-developed stack rings apparatus was used to study the behavior of interface between two filling materials in embankment $(\mathrm{Hu}$, 2007). It's found that the location of shear zone shifts with normal stress. Under small normal stress condition, the failure surface exists in the upper layer (filter); while the normal stress is larger than the critical value, the failure surface moved to the sublayer (clay). They believed that the shearing transition zone is the combined interaction result of filter, clay and the mixed coating. In addition, direct shear tests were carried out on the interface between sand and clay (Chen, 2012). The results show that the failure surface locates either in sand, clay or exactly on the interface.

However, in some slide cases, the failure surfaces are found locating at the interface between expansive soil and drainage liner (normally as sand). As we know, there are lots of cases for the interaction of two different granular material layers such as in rock-fill dam, embankment of highway, retaining wall, etc. The destructions of these projects do not happen along the 
interfaces. Is that because some special characteristics of the interface between expansive soil and drainage material? Maybe the swelling and softening properties of the expansive soil itself and drainage circumstance make the shearing behavior on the interfaces more complicated and become the weakest part of the whole system, where the shear resistant ability is the lowest. In order to get a better understanding for the shearing behavior on the interface between expansive soil and drainage material, a series of direct shear tests are conducted for special prepared samples under wetting and drying cycles. Meanwhile, the influences of samples' saturation methods are compared.

\section{LABORATORY STUDY}

\subsection{Testing materials properties}

The expansive soil used is from the site in South-to-North water diversion project in Xinxiang, Henan, China. The contacted material is a kind of well graded coarse sand (GB/T 50145-2007). The main characteristic parameters for testing materials are listed in table 1. Fig. 1 shows the particle size distribution curve for the sand.

\begin{tabular}{ccccc} 
Table 1. Main physical and mechanical parameters of materials \\
\hline $\begin{array}{c}\text { specific } \\
\text { gravity } \\
\mathrm{G}_{\mathrm{s}}\end{array}$ & $\begin{array}{c}\text { maximum } \\
\text { dry density } \\
\rho_{\mathrm{dmax}}\left(\mathrm{g} / \mathrm{cm}^{3}\right)\end{array}$ & $\begin{array}{c}\text { optimum } \\
\text { moisture } \\
\text { content } \\
\omega_{\mathrm{op}}(\%)\end{array}$ & $\begin{array}{c}\text { free } \\
\text { swelling } \\
\text { ration } \\
\delta_{\mathrm{ef}}(\%)\end{array}$ \\
\hline $\begin{array}{c}\text { expansive } \\
\text { soil }\end{array}$ & 2.75 & 1.60 & 23.3 & 85.25 \\
\hline sand & 2.65 & 1.68 & - & 0 \\
\hline
\end{tabular}

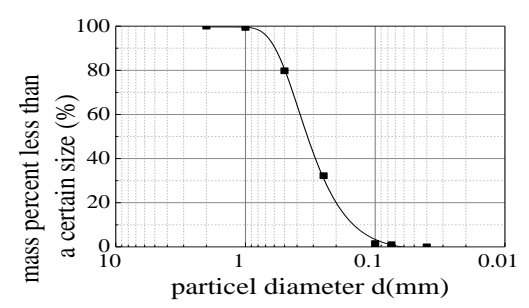

Fig.1. Particle size distribution curve for sand

\subsection{Sample Preparation}

The prepared samples are $\Phi 6.18 \mathrm{~cm} \times 2 \mathrm{~cm}$. The schematic drawing of the sample preparation and photo are shown as figure 2 .

The preparation steps are as following, where the compaction steps for two layers simulate the formation process of the interface.

(1) About $5500 \mathrm{~g}$ of expansive soil with about $23 \%$ moisture content are prepared, then are put into a sealed plastic bag for 24 hours;

(2) Before the compaction of sand layer, a piece of fabric geotextile in $8 \mathrm{~cm} \times 8 \mathrm{~cm}$ is trapped by rubber bands to the side of ring model at the bottom. Then a piece of filter paper, $6.18 \mathrm{~cm}$ in diameter, is put in;

(3) According to $95 \%$ of $\rho_{d \max }, 48 \mathrm{~g}$ of dry sand are put onto the filter paper, and then compacted to $1 \mathrm{~cm}$ in height by a wooden hammer. A brush is used to smooth the surface of the compacted sand slightly;

(4) According to $1.41 \mathrm{~g} / \mathrm{cm}^{3}$ of dry density, $52 \mathrm{~g}$ of prepared expansive soil are put onto the compacted sand layer. Then the whole sample is compacted to 2 $\mathrm{cm}$ in height.

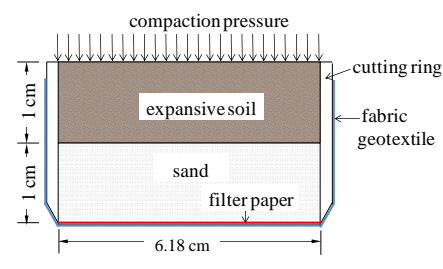

(a) Schematic drawing

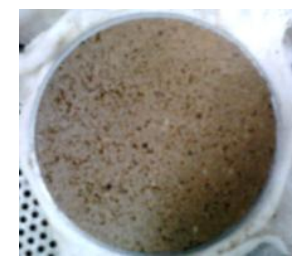

(b) Photo
Fig.2. Sample preparation

\subsection{Wetting-drying circulation methods}

Artificial wetting-drying cycles are conducted to simulate the weathering influence, which will induce to cracks growing in expansive soil and make further interaction between the two materials.

For saturation process, prepared sample is put into a stainless saturator with a porous stone at the bottom, then another porous stone is put on the top. Then the saturator is immersed into water for 24 hours.

Comparison is carried out for two saturation methods under confined/unconfined conditions. For confined saturation condition, the samples' swelling are fully restricted by locking the saturator on both bottom and top; while the samples are able to swell freely in height during saturation for unconfined saturation condition.

An electric heater and an air fan are used for drying process. Saturated samples are placed under the electric heater for 2 hours, and then blew for 2 hours with the air fan, in which way repeated for 3 times to complete one drying step.

The samples are conducted for at most 5 times of wetting-drying cycles.

\subsection{Test procedure}

The prepared samples after different times of wetting-drying cycles are saturated and then taken for quick shear test, with $1.2 \mathrm{~mm} / \mathrm{min}$ of shearing rate, under 50,100, 150 and $200 \mathrm{kPa}$ of normal pressure. The shear strength is recorded as the final stable value or the peak one of the shear stress from $\tau \sim \delta$ curve.

\section{TESTS RESULTS DISCUSSION}

\subsection{Shearing Behaviours}

Figure 3 shows the photos of the failure surface under confined saturation condition after twice wetting-drying cycles. It is found that the failure surface just locates at the interface at beginning, and 
then it shifts a certain depth into the sand liner as the shearing displacement increasing. Small vertical dilatancy displacement can be noticed. It seems the top layer of sand in the lower box adheres to expansive soil in the upper box. The failure surface is found not exact horizontal but slightly lower at the end of shearing direction, which means some sand moves/rotates along the shearing direction.

The shear stress-displacement relationships of the saturated samples of expansive soil, sand and expansive soil-sand interface are compared in Fig. 4. It shows that the shearing behaviors of the interface are strain-hardening, which is similar with expansive soil but different from sand. The strength of interface locates reasonably between those of expansive soil and sand.

As we know, the higher density of sand, the more difficulty for the particles to move. Sand particles are forced to rotate/roll over the others when the shearing displacement reaches to a certain value, which results in dilatancy effect and the peak shearing stress. And as shearing displacement increases, the particles rearrange to a relatively stable structure, which leads to the decreasing of shearing stress (Guo, 1987). The testing results above indicate that there exists a shear band (Babak, 2012). The movement of sand on the interface is restricted by expansive soil and embedded into expansive soil, forming a thin mixture layer. This mixture layer inherits more from expansive soils rather than from sand, and behaves strain-hardening during shearing process.

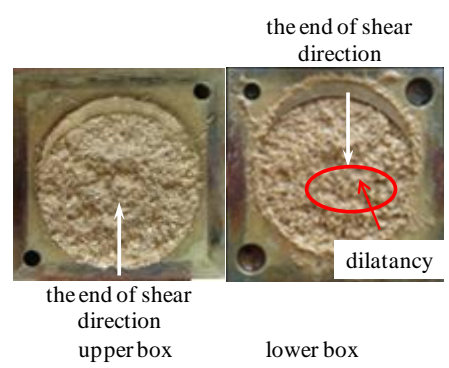

Fig.3. Shape of the failure surface

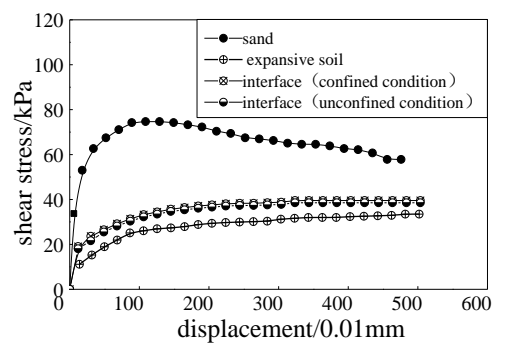

Fig.4. Shear stress vs. displacement curves $(\mathrm{P}=100 \mathrm{kPa})$

\subsection{Shear Strength - Friction Angle}

Fig. 5 shows the variation of the friction angles for samples with different times of wetting-drying cycles prepared by two saturation methods. It shows the friction angles for the samples prepared under confined saturation condition are about 0.4 to 9.7 degrees greater than those under unconfined saturation condition. And as the number of wetting-drying cycles increases, the friction angle increases for the samples under confined saturation condition, while under unconfined saturation condition it increases at beginning and decreases later. The maximum fiction angle for the samples under unconfined saturation condition occurs at the $2^{\text {nd }}$ round of wetting-drying cycles.

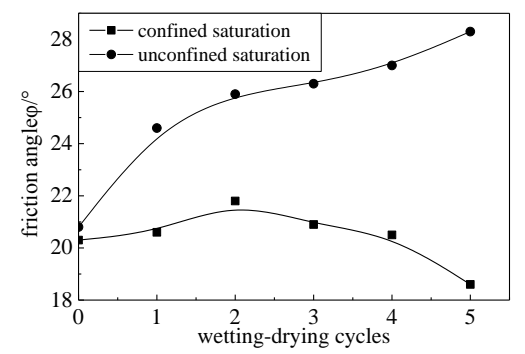

Fig.5. Friction angle vs. wetting-drying cycles curves

The phenomena of friction angle changing as wetting-drying cycling is quite different from our traditional understanding about expansive soils. Previous experiments studies show that the strength of expansive soils will irreversibly reduce during weathering, as a result of cracks growing. Furthermore, the strength's decreasing comes mainly from decrease of cohesion, while the friction angle just changes slightly (Yin, 2011). So, what leads to higher strength for the interface during wetting-drying cycling? It is noticed that the more times of wetting-drying cycles, the thicker mixture layer at the interface. It means that more sand merge into expansive soil due to wetting-drying circulations. As a result of increasing content of sand in shear zone, the friction resistant increases when samples enduring more times of wetting-drying cycles. The final result on the interface after wetting-drying cycles is a combination of the two effects: micro-structural damage (cracks development) and combination integration (interaction enhancement).

Under unconfined condition, the expansive soil is freely to swell or shrink when water content changes. At the first several times of wetting-drying cycles, the interaction enhancement seems to be the overwhelming effect, which leads to friction angle increasing. But later, without confined restrict, swelling deformation induces pore/cracks growing and lower density, which results in decreases of friction angle at the end.

While under confined condition, the interaction enhancement becomes stronger because of confined pressure. As wetting-drying cycling, the confined pressure helps more sand merging into the mixture layer and leading to higher density than under unconfined condition. Even though there are pore/cracks growing at the same time, the pore/cracks development encounters more difficulty than that under 
unconfined condition, because of less movement of soil particles due to the friction restriction on the surface of expansive soil. On the other hand, the developed pore/cracks are more easily filled with sand under confined pressure. Both the effects finally result in the increases of friction angle.

\subsection{Shear Strength - Cohesion}

Fig.6 shows that the cohesion keeping growing as wetting-drying cycling under unconfined saturation condition, while it changes just a little bit and almost remains zero under confined saturation, which is quite different from previous reported results (Yin, 2011). According to published papers, most researchers believe that, for expansive soil, the cohesion reduces and the friction angle keeps almost constant as wetting-drying cycling.

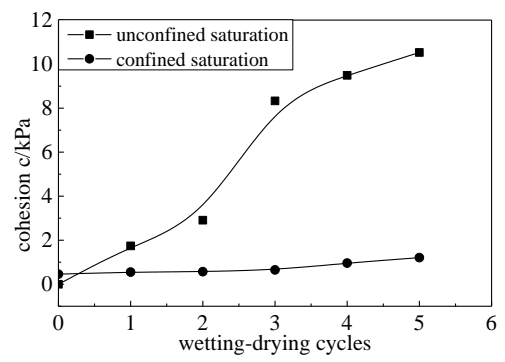

Fig.6. Cohesion vs. wetting-drying cycles curves

As mentioned above, the failure surface extent to a certain depth in sand linear instead of exactly on the interface when shearing, which might be the reason why the cohesion remains almost zero under confined condition. While under unconfined condition, the mixture enhancement is weaker, which leads to shearing surface closer to the exact interface and the cohesion inherits more from expansive soil. As we know, the action of the wetting-drying cycles on expansive soils is likely a periodic loading-unloading function, which induces a stress history for the soil, i.e. the soil becomes slightly over-consolidated. And for over-consolidated soil, its cohesion increases with the pre-consolidation stress, which relates to the times of wetting-drying cycles here. Another reason for the increasing of cohesion under confined condition is that the shearing strength curve $\tau_{f}-\sigma$ does not show perfect linear relationship. The shearing strength curve $\tau_{f} \sigma$ shows reclining at higher normal stress. And the difference between reclining and linear tendency increases as the wetting-drying cycling.

\section{CONCLUSIONS}

A series of direct shear tests are carried out on the interfaces between expansive soil and sand liner during wetting-drying cycles. Upto 5 times of wetting-drying cycles are applied on the samples under confined and unconfined saturation conditions. Based on tests results, here comes to main conclusions as following:

(1) The failure surface locates at the interface between expansive soil and sand at beginning and then shifts a certain depth into the sand liner as shearing displacement increasing. The interface behaves strain-hardening for shear stress-displacement curve.

(2) The friction angels under confined saturation condition are about 0.4 to 9.7 degrees greater than those of under unconfined saturation condition at the same wetting-drying cycle. As wetting-drying cycling, the friction angle increases under confined saturation condition, while it increases at beginning and then decreases under unconfined saturation condition.

(3) The interface shear behavior is the combination results of two aspects: sand particles merging into expansive soil and samples compacted by swelling pressure, which increases the density of the "shear band" and samples, and pore/cracks growing, which destroys the integrity.

\section{ACKNOWLEDGEMENTS}

This research was sponsored by "the National Natural Science Foundation of China" (Grant No. 51378008), "the Fundamental Research Funds for the Central Universities" (Grant No. 2014B04914) and "the National Science \& Technology Pillar Program during the Twelfth Five-year Plan Period" (Grant No. 2011BAB10B04).

\section{REFERENCES}

1) Boulon M. (1989): Basic features of soil structure interface behavior, Computers and Geotechnics, 7(1), 115-131.

2) Chen K., Jiang Z., Sun Q. (2012): Experiment on mechanical behavior of interface between sand and clay, Coal Geology \& Exploration, 40(4), 56-59 (In Chinese).

3) Desai C S, Drumm E C, Zaman M M. (1985): Cyclic testing and modeling of interfaces[J]. Journal of Geotechnical Engineering, 111(6), 793-815.

4) Ebrahimian B, Bauer E. (2012): Numerical simulation of the effect of interface friction of a bounding structure on shear deformation in a granular soil, International Journal for Numerical and Analytical Methods in Geomechanics, 36:1486-1506.

5) Guo Q. (1987): Experimental research on shear strength of coarse grained soil, Journal of Hydraulic Engineering, 5, 59-66 (In Chinese).

6) Hu L., Ma J., Zhang B., Yu Y. (2007): Scaling effect on the mechanical behavior of the interface between coarse-grained materials and a structure, Tsinghua Science and Technology, 47(3), 327-330 (In Chinese).

7) Ministry of Construction of P.R. China (2007): Standard for engineering classification of soil, GB/T 50145-2007, China Planning Publishing House, 8-10 (In Chinese).

8) Tejchman J, Wu W. (1995): Experimental and numerical study of sand-steel interfaces, International journal for numerical and analytical methods in geomechanics, 19(8), 513-536.

9) Yin Z., Xu B. (2011): Slope stability of expansive soil under fissure influence, Chinese Journal of Geotechnical Engineering, 33(3), 454-459 (In Chinese). 